\title{
A (im)possibilidade do uso de Lethal Autonomous Weapon System frente ao direito internacional humanitário e a ética
}

\section{The (im)possibility of the use of Lethal Autonomous Weapons Systems under international humanitarian law and ethic}

\section{HAIDE MARIA HUPFFER GABRIEL CEMIN PETRY}

\section{INTRODUÇÃO}

Com o desenvolvimento constante e desenfreado de novas tecnologias, a inteligência artificial é, hoje, uma realidade, e o implemento de sistemas de inteligência artificial faz-se presente nas mais variadas áreas do conhecimento, indo desde o atendimento ao cliente e finanças à biomedicina $\mathrm{e}$ melhoramento humano, por exemplo. O campo militar foi igualmente beneficiado pelo desenvolvimento de sistemas de inteligência artificial, acarretando, por conseguinte, a incorporação e desenvolvimento de novos tipos de armas, munições e mísseis inteligentes.

Neste contexto surgem as Lethal Autonomous Weapon System (LAWS), que são armas capazes de, por conta própria, ou seja, sem a interferência humana, atingir seus objetivos militares - sendo dotadas de certa autonomia para realizar suas funções. Fazem-se presentes, neste sistema de inteligência artificial, elementos de machine learning e decision-making, que implicam na capacidade da arma de selecionar, identificar, descrever e, inclusive, priorizar alvos, bem como atacá-los sem que haja interferência humana para tanto.

Haide Maria Hupffer - Pós-Doutora em Direito pela Unisinos. Doutora em Direito pela Unisinos. Docente e Pesquisadora no Programa de Pós-Graduação em Qualidade Ambiental e Curso de Direito da Universidade Feevale.

Líder do Grupo de Pesquisa Direito e Desenvolvimento do CNPq/Feevale

Gabriel Cemin Petry - Bacharelando em Direito na Universidade Feevale. Participante do Programa de Iniciação Científica da Universidade Feevale. 
Visto isso, a implantação desse tipo de tecnologia nos campos de batalha modernos ocasiona novos questionamentos e, por decorrência, demanda novas análises acerca de seu uso e desenvolvimento, inclusive no campo do Direito e da Ética. Delineiam-se, dentre outros, as seguintes questões: as armas serão capazes de identificar objetivos civis de objetivos militares? Como distinguirá populares e civis de agentes militares; os combatentes ativos e fora de combate; os hospitais de bases militares? Será a máquina capaz de seguir princípios éticos para tomada de decisões de vida ou morte?

Desta forma, o presente artigo ocupa-se da análise das Lethal Autonomous Weapon System (LAWS) ante o Direito e a Ética, ou, especificadamente: a possibilidade, ou não, de seu uso e desenvolvimento em consonância com os ditames do (i) Direito Internacional Humanitário, que dita as regras para uma situação de conflito armado, e da (ii) Ética da responsabilidade. Frente à velocidade com que o desenvolvimento tecnológico avança, bem como as incertezas do futuro quanto ao uso dos referidos sistemas de armas autônomos, tais questionamentos mostram-se imprescindíveis, cabendo ao Direito e à Ética o preenchimento destas lacunas, a fim de que se evitem danos ao ser humano e suas obras, animais e ao meio ambiente.

Com o fim de identificar a possibilidade do uso e desenvolvimento das LAWS perante o Direito Internacional e a Ética, adota-se o método de investigação dialético, pleiteando-se, assim, uma análise do real, a qual se dará por meio de uma apuração essencialmente bibliográfica, documental e legal.

Desta forma, analisar-se-á, primeiramente, conceitos básicos acerca do termo "inteligência artificial” e o beneficiamento histórico da indústria da guerra com sistemas de inteligência artificial, para, então, se passar ao exame das Lethal Autonomous Weapon System. Feito isso, ingressa-se ao exame das normas que regulam os cenários de conflito armado, internacional ou não: o jus in (ad) bellum e o Direito Internacional Humanitário. Consequentemente, abordar-se-ão considerações atinentes ao uso e desenvolvimento das LAWS, primeiramente, em observância das normas de Direito Internacional, e, após, ante as implicações da (nova) Ética, oportunidade em que serão apresentadas as conclusões do presente artigo.

\section{INTELIGÊNCIA ARTIFICIAL E A INDÚSTRIA BÉLICA: O SURGIMENTO DAS LETHAL AUTONOMOUS WEAPON SYSTEM}

Inicialmente, faz-se pertinente atentar à dificuldade de apontar uma definição para o termo "inteligência artificial” que seja inteiramente capaz de abarcar todas as considerações atinentes à temática, dado a tamanha ampli- 
tude e abrangência da matéria, sendo o conceito de inteligência igualmente dependente de um contexto característico (Faggella 2018).

Um ponto comum entre as definições já existentes acerca da Inteligência Artificial é "la idea de crear y dar forma a programas de ordenador o también a máquinas que sean capaces de desarrollar conductas que serían consideradas inteligentes si las realizara un ser humano" (Rodriguez 2018, 145). Subjacente a esse ponto, duas características básicas despontam em todo o sistema de inteligência artificial, quais sejam: (i) a capacidade do sistema de aprender (machine learning); (ii) a capacidade de manejar a incerteza e uma provável informação, bem como formar conceitos com base em combinações criadas a partir de um processo de racionalização lógica e intuitiva (Rodriguez 2018, 146).

Ante o questionamento acerca de como definir o conceito de inteligência artificial, Russel e Norvig (2009, 5-8) organizam em quatro categorias algumas definições acerca do tema, sendo elas: (i) IA são sistemas que pensam como humanos (thinking humanly), quer dizer, possuem um modelo cognitivo semelhante ao pensamento humano; (ii) IA são sistemas que agem como humanos (acting humanly), tendo capacidade de comunicar-se em língua humana, armazenar e representar o conhecimento, racionalização automatizada para usar tais informações para responder perguntas, resolver problemas e chegar a conclusões com base na informação apresentada, bem como a habilidade de adaptar-se a novas circunstâncias e detectar e superar padrões (machine learning); (iii) IA são sistemas que pensam de forma racional (thinking rationally), isto é, através de uma forma de pensamento lógico, podendo, por exemplo, identificar, descrever e solucionar problemas, e; (iv) IA são sistemas que agem de forma racional (acting rationally), utilizando suas "habilidades cognitivas" para atingir seus objetivos.

Levando em consideração os conceitos de Russel e Norvig (2009), Scherer (2016), em sua tentativa de responder o que seria, de fato, inteligência artificial, oferece uma definição para o conceito do termo, sugerindo que IA "refere-se a máquinas que são capazes de realizar tarefas que, se realizadas por humanos, seriam consideradas como exigentes de inteligência". Com efeito, a terminologia atinente à "inteligência" compreende a existência de recursos como (i) a capacidade de certa entidade ou agente de interagir em determinado ambiente, (ii) a habilidade de certa entidade ou agente, observando determinados critérios, de obter sucesso em uma tarefa ou objetivo, e (iii) a capacidade de aprender, adaptar-se e demonstrar flexibilidade em uma ampla gama de ambientes e cenários, tratando-se, in casu, de uma forma autêntica de inteligência (Faggella 2018). Somando estes três atributos, Legg e Hutter (2006) sugerem o emprego da definição 
de inteligência como forma de medida da capacidade ou habilidade de um agente para obter êxito em objetivos em larga variedade de ambientes.

Sistemas de IA podem ser caracterizados através das seguintes formas:

- semanticamente, sendo divididos em inteligência artificial forte (Strong $A I$ ), podendo corresponder a níveis de inteligência compatíveis a de humanos, e inteligência artificial fraca (Weak $A I)$, espelhando processos de pensamento e sendo útil ferramenta para descobrir e aprimorar a mente humana;

- conforme as soluções derivadas da aplicação de sistemas de inteligência artificial que podem apresentar-se de forma simples (comumente encontrada em plataformas comerciais básicas); complexa (otimizando sistemas de trabalho através de previsões de eventos ou cenários com base em dados históricos, monitoramentos, gerenciamentos de segurança); muito complexa (trabalhando em todo o processo de coleta, gerenciamento e análise de informações, podendo propor soluções para futuros de curto e médio prazo);

- segundo a continuidade da inteligência artificial (AI Continuum): Inteligência Assistida (Assisted Intelligence), responsável pela execução de tarefas mundanas com mais eficiência que humanos; Inteligência Aumentada (Augmented Intelligence), colaborando de forma mais "autêntica", na qual os sistemas e humanos aprendem um com o outro e refinam processos; Inteligência Autônoma (Autonomous Intelligence), trata-se de um sistema capaz de adaptar-se ao longo do tempo, aprender e assumir processos inteiros em um sistema específico (Faggella 2018).

A IA projeta-se para gerenciar desafios sistêmicos complexos e globais, dentre os quais está a possibilidade de controlar as emissões globais de $\mathrm{CO}_{2}$, modelagem de clima, cenários nucleares, prevenir crimes violentos e atos terroristas e gerenciar o controle do tráfego aéreo global. Parte dos aplicativos de IA são dotados de uma superinteligência para resolver problemas complexos em escalas para além da capacidade humana, superando desafios inimagináveis, como tutores inteligentes (dotados de afetividade e emoções), nanorrobôs para substituir o sangue humano; criação de um supercérebro global para conectar redes de cérebros humanos individuais e inteligências artificiais para possibilitar o pensamento coletivo”, nanorrobôs neurais ("conectar o neocórtex do cérebro humano a um "neocórtex sintético’ na nuvem”), interface cérebro humano/nuvem (“conectar neurônios e sinapses no cérebro a vastas redes de computação em nuvem em tempo real”) (Inovação Tecnológica 2019). Entretanto, a IA pode levar a 
humanidade a cenários catastróficos. Especialistas alertam sobre os riscos da segurança global se "criminosos conseguirem hackear ou confundir os aplicativos de IA" e essa perspectiva passa a exigir "discussões de quadros éticos e de valores que orientem o desenvolvimento e a implementação de IA" (Schwab 2018, 178-9).

Um dos campos afetados pelo desenvolvimento da IA foi o militar, que igualmente sofreu consideráveis avanços. A título exemplificativo, hoje existem robôs projetados e programados para substituir a ação humana no indesejável e extremamente perigoso trabalho de desarmar um explosivo. Dentre outros avanços neste campo, destaca-se, pois, a criação de armas que funcionam com autonomia, como é o caso das Lethal Autonomous Weapon System (LAWS), incluindo mísseis inteligentes e drones autônomos. (Rodriguez 2018)

A indústria bélica e militar é uma das mais beneficiadas pelo desenvolvimento da IA (Rodriguez 2018). Assim, o incremento de sistemas e máquinas dotadas de inteligência artificial consequentemente passou a ser cada vez mais explorado pela indústria da guerra no decurso do tempo e, segundo sustenta Hagström (2016, 23), sistemas de armas autônomas, por exemplo, têm sido utilizados por forças armadas de Estados por mais de um século em conflitos armados. Na Primeira Guerra Mundial, foram desenvolvidos torpedos aéreos e mísseis guiados, tais como "terra-terra” (ground-to-ground), que já detinham certo grau de autonomia. Com a Segunda Guerra Mundial foram desenvolvidos novos mísseis teleguiados e, na atualidade, "armas com alto grau de automação, ou teleguiados, podem facilmente ser encontrados no inventário da maioria dos Estados" (Hagström 2016, 23).

Em breve síntese, desde 1960 houve significativos desenvolvimentos nesta área, sendo aperfeiçoados sistemas de mísseis teleguiados com maior navegação e mobilidade. Entre 1970 e 1980, amplificou-se o desenvolvimento de sistemas capazes de identificar alvos, discriminar imagens, bem como priorizar determinados tipos de alvos. Na atualidade, com os avanços de sistemas de machine learning, reconhecimento e classificação de alvos, sistemas de inteligência artificial são capazes de realizar ataques sem qualquer tipo de intervenção humana (Roff 2016).

Historicamente, consoante sustenta Boulanin, a indústria das armas tem apostado no desenvolvimento de dois tipos de sistemas de armas, a saber: (i) sistemas de defesa automática (automatic defense systems), como, por exemplo, o sistema holandês de proteção de navios contra mísseis manobráveis Goalkeeper Close-In Weapons System (CIWS) e as sentinelas Super aEgis anti-personnel sentry weapon system; (ii) mísseis e munições inteligentes, como, por exemplo, os mísseis inteligentes contra navios Long Range 
Anti-Ship Smart Missile (LRASM) e Harpy loitering munitions produzida por indústrias armamentistas do Estado de Israel (Boulanin 2016, 25).

Os primeiros fatores que motivaram o desenvolvimento e o uso de sistemas de armas autônomos na guerra foram: (i) a multiplicação da força pelo uso da robótica, uma vez que menos soldados são necessários para uma missão, podendo um único "soldado" realizar tarefas que necessitam de vários; (ii) a expansão do espaço de batalha, na medida em que robôs permitem a condução de combates em áreas maiores; (iii) a extensão do alcance do "soldado", uma vez que o uso da robótica permite a um "soldado" um alcance muito maior no espaço de batalha, seja através da visão ou da capacidade de atingir alvos mais distantes, e, por fim; (iv) a redução de baixas em combate, eis que o a implementação gradativa de sistemas tecnológicos substituiria soldados humanos em missões mais perigosas (Arkin 2017, 37).

A história tem mostrado que a evolução no campo tecnológico e sua aplicação em conflitos armados acaba por traçar as linhas mestras de como as guerras serão lutadas. Desta forma, observando os avanços nos sistemas de armas e os novos métodos criados pelo homem, com especial atenção aos avanços no desenvolvimento de armas dotadas de "autonomia", faz-se necessário estabelecer contextos para a aplicabilidade militar — de forma a igualmente observar-se as implicações do Direito Internacional Humanitário e da ética (Lele 2017, 57).

As Nações Unidas publicaram, no ano de 2015, um documento que reflete a preocupação com a regulamentação de veículos aéreos não tripulados que desafiam os princípios humanitários e que, pela proliferação e utilização generalizada, aumentam em larga escala a segurança. Dentre os veículos dotados de autonomia e sistemas de IA estão os drones (robôs voadores) para executarem funções de navegação complexa e realizar entregas de armas de destruição em massa e, por isso, as Nações Unidas levantam questões éticas sobre como saber se é um simples drone ou se é um robô voador dotado com um sistema de armas autônomas letais. Nas pautas internacionais, a discussão sobre a necessidade de os seres humanos tomarem decisões sobre LAWS tornou-se questão inadiável. No centro das discussões está o alerta de que o controle humano seja um pré-requisito para armas dotadas de IA. Funções como decolar, voar para a área alvo, identificar alvos, armar armas para o lançamento podem ser totalmente autônomos, especialmente se o sistema operar em mais de um modo, como, por exemplo, semi-autônomo ou totalmente autônomo, em razão da segmentação prevista para o ataque ou pela falta de transparência/informação por parte do usuário sobre as potencialidades. O alerta da ONU é no sentido de que o desenvolvimento e o uso de sistemas de armas de guerra 
autônomos, por exemplo, em drones, representam desafios enormes para a ordem internacional e o direito à vida (United Nations 2015).

A pesquisa e a aplicação em IA está progredindo rapidamente e não se vislumbra nenhum obstáculo em futuro próximo, como pode-se observar no desenvolvimento das denominadas Lethal Autonomous Weapon System (LAWS), que é o tema central do presente estudo. LAWS são essencialmente armas dotadas de autonomia, ou seja, são capazes de identificar alvos e interceptá-los ou destruí-los (ICRC 2016b). O Comitê Internacional da Cruz Vermelha define os sistemas de armas autônomas como "qualquer sistema de armas com autonomia em suas funções críticas”. Este sistema de armas foi desenvolvido para ter capacidade de "selecionar (procurar ou detectar, identificar, rastrear) e atacar (usar força contra, neutralizar, causar danos ou destruir) alvos sem intervenção humana” (ICRC 2016b).

O conceito do termo "autonomia" existente nas LAWS concerne basicamente na condição de autogovernança (self-governance) da arma e, igualmente, na capacidade desta para realizar tomada de decisões (decision-making) - levantando questões de toda sorte, éticas e morais, relativas à capacidade para a tomada de decisões sobre vida ou a morte de pessoas. Em termos técnicos, o emprego do termo "autonomia" é utilizado para apontar um sistema inteligente capaz de agir em ambientes desconhecidos ou em situações imprevistas sem a influência humana (Hagström 2016, 23). As LAWS, portanto, funcionam por conta própria, quer dizer, sem que haja sobre o sistema a intervenção humana, detendo, uma vez que ativados, a liberdade para identificar e atacar alvos - sendo, por decorrência de tal característica, também chamadas de sistemas de arma fire-and-forget (Lele 2017, 58).

A questão de autonomia das Lethal Autonomous Weapon System é enfrentada da seguinte forma por Roff $(2016,33)$ : (i) "autonomia nas 'funções críticas', ou aquelas funções relacionadas com a seleção e engajamento de alvos"; (ii) sistemas que são dotados de "softwares de reconhecimento de alvo automático, possibilitando que eles localizem o alvo por conta própria, correspondendo esse alvo a uma biblioteca de identificação de alvos ou uma base de dados e, em seguida, dispare no alvo"; (iii) sistemas dotados com "vários recursos de sensores que permitem a eles perceberem o seu entorno e, então, reconhecer alvos em potencial (como radares ou tanques inimigos)"; (iv) os sistemas "são restringidos aos tipos de alvos que podem promover ataques, pois somente aqueles alvos que correspondam à biblioteca de identificação de alvos seriam vistos como compatíveis" com a intenção projetada. Constituem exemplos de sistemas que possuem a referida tecnologia: a Goalkeeper Close-in Weapon System (sistema holandês), Iron Dome (sistema israelense), Kashtan Close-in Weapon System (sistema rus- 
so), a Advanced Modular Armour Protection Active Defence System (AMAPADS) (sistema russo), a Quick Kill (sistema dos EUA), MK 60 CAPTOR Encapsulated Torpedo (sistema dos EUA), aEgis I and II and Super aEgis I and II (sistema coreano) e Sentry Tech Stationary Remote-Controlled Weapon Station (sistema israelense) (ICRC 2016b).

Em razão da autonomia e da liberdade para tomada de decisões, coleta de informações, formação de conclusões e resolução de problemas, sistemas de IA podem encontrar e analisar mais possibilidades do que um ser humano poderia, bem como examinar possíveis soluções para um problema que humanos sequer ponderariam. Ainda assim, adverte Scherer, no que tange à ação inesperada de um sistema de inteligência artificial, "até o momento, a ação inesperada de Inteligência Artificial tem sido bastante limitada em seu escopo; um programa de xadrez pode realizar um movimento inesperado, mas ainda não estaria fazendo outra coisa além de jogar xadrez" (Matthew 2016, 363-366). Ainda que sejam tranquilizadoras as observações de Scherer (2016), não se faz prudente desconsiderar o fato de que se está tratando de armas letais, as quais são detentoras de tal "liberdade" e "autonomia”, fato que volta a atenção a análises de risco, bem como a observância do uso das mesmas ante ao Direito e a Ética (Matthew 2016, 363-366).

Por outro lado, considerando que a problemática referente à autonomia guarda seu lado tecnológico e o seu lado humano, focar os debates sobre autonomia a partir de uma perspectiva mais humana, segundo sustenta Vignard (2016, 65-66), tem-se mostrado ser benéfico, uma vez que esse debate é mais consistente para a aplicação de normas de Direito Humanitário (na medida em que requerem certo nível de julgamento humano). Além disso, trata-se de conceito amplo o suficiente para integrar considerações éticas, sendo a interação homem-máquina e "os ditames de consciência pública" muitas vezes portadoras de abordagens que tão somente consideram a tecnologia ou a lei.

Conforme abordado, o comportamento ético é próprio do Direito Internacional Humanitário (requerendo um padrão básico de compostura e humanidade) (Rezek 2018) e a tarefa de agir conforme esta ética é uma tarefa que mesmo para seres humanos não é fácil; entretanto, fazem-se presente discursos, ao tratar da "autonomia ética", que asseveram que sistemas autônomos poderão, no futuro, realizar suas tarefas melhor que humanos, ainda que sob a ótica da ética. As razões que sustentam tal argumento apoiam-se em fundamentos como, por exemplo: (i) sistemas de inteligência artificial não precisam proteger eles mesmos, uma vez que não detêm um senso de autopreservação, como o humano; (ii) os sistemas não detêm sentimentos, os quais podem obscurecer os sentidos do soldado durante o conflito armado; (iii) a maior capacidade dos sistemas de relacio- 
nar e processar informações e com mais velocidade do que humanos, antes mesmo de responder a ação com força letal (Arkin 2017, 39).

Em que pese o exposto, há também, em paralelo, argumentos contra o emprego de sistemas de IA capazes de empregar força letal contra alvos. Neste sentido, Asaro (2012) aponta que a justiça não pode ser automatizada, bem como a decisão de matar, por exemplo, num cenário de conflito, tão somente pode ser considerada legítima se não for arbitrária, sendo exigido o julgamento humano, requisito necessário para a tomada de decisões de vida ou morte (ou legal killing); assim, "como uma questão de preservação da moralidade, dignidade, justiça e lei humana, não podemos aceitar um sistema automatizado tomando a decisão de tirar uma vida humana" (Asaro 2012, 708).

Um sistema de armas pode ser tanto ofensivo quanto defensivo; todavia, devido à natureza da guerra, espera-se que sistemas de armas com autonomia pertençam à categoria de armamento considerado como defensivo. Consoante argumenta Lele (2016), no que tange a sistemas de mísseis autônomos, nenhum sistema pode ser considerado como 100\% autônomo; entretanto, na atualidade, existem sistemas defensivos capazes, de forma totalmente autônoma, de selecionar e atacar alvos, como, por exemplo, os counter-rocket, artillery and mortar systems; Iron Dome, anti-missile systems, Terminal High Altitude Aerial Defense (THAAD), S-400, dentre outros (Lele 2016, 31-2).

As LAWS podem ser classificadas em três grupos, baseando-se na finalidade do sistema. O primeiro trata-se de armas defensivas anti-material (anti-material defensive weapons), usada para proteção de veículos, localidades e áreas em ataque de mísseis, foguetes, morteiros, etc. A segunda atine aos sistemas de armas ofensivas (offensive weapon systems), incluindo mísseis e torpedos que têm autonomia para seleção e ataque de alvos após o lançamento, como é o caso das loitering munitions e dos torpedos encapsulados, dentre outras armas que possuem mais liberdade de ação e espaço. A terceira são as armas contra pessoas (anti-personnel weapons), tendo autonomia para selecionar e atacar alvos, como por exemplo sentrys usadas para defender localidades e sítios de segurança (ICRC 2016a).

Conforme Roff (2016, 34-5), atualmente existem três áreas de potencial desenvolvimento das LAWS, quais sejam: plataformas únicas (single plataforms); combinações de sistemas legados (combinations of legacy systems); e sistemas de arma modular (modular weapon system). Em que pese tais disposições, a evolução e o desenvolvimento de novas tecnologias, tornando-as mais complexas e mais autônomas, podem implicar maiores dificuldades em garantir-se que os sistemas não falhem (Righetti 2016, 36-7), bem como correm o risco de comprometimento da previsibilidade 
e confiabilidade da arma. Alguns desenvolvimentos "podem fazer com que sistemas de armas autônomas tornem-se menos previsíveis". Como exemplo, a ICRC (2016a) cita: (i) o aumento da mobilidade, quando o sistema de armas encontra "ambientes mais variados por maiores períodos de tempo"; (ii) a maior adaptabilidade — neste caso, os sistemas podem definir "seus próprios objetivos ou mudam o seu funcionamento em resposta ao ambiente (por exemplo, um sistema que defende a si mesmo em um ataque) ou até mesmo incorporam algoritmos de aprendizado"; (iii) "o aumento da interação de múltiplos sistemas de armas em enxames auto-organizados”. Afora a diminuição da previsibilidade das LAWS, é possível surgirem outros problemas relacionados à validade dos testes para garantir a sua confiabilidade (ICRC 2016a).

Ante tais disposições, no que tange ao futuro das LAWS, armas autônomas que sejam capazes de estipular seus próprios objetivos, aprender e adaptar suas funções seriam, por natureza própria, imprevisíveis. Nesta hipótese, a utilização deste tipo de armamento acarretaria problemas quanto à previsibilidade e confiabilidade da arma em relação aos alvos de um ataque específico (ICRC 2016a).

Dadas as incertezas do futuro, bem como a altíssima responsabilidade do desenvolvimento das LAWS, ressalta-se a pertinência das discussões acerca do uso deste tipo de armamento em consonância com o Direito, em especial o Direito Internacional Humanitário e a Ética.

\section{AS IMPLICAÇÕES DA TEORIA DA GUERRA JUSTA E DO DIREITO INTERNACIONAL HUMANITÁRIO NO USO DAS LETHAL AUTONOMOUS WEAPON SYSTEM}

Inicialmente, interessa mencionar que a Teoria da Guerra Justa foi um importante elemento das estruturas éticas nas relações entre Estados soberanos, bem como foi moldada no direito internacional. Segundo articula a referida teoria, na concepção de Frost (2005), o caráter justo ou injusto da guerra depende da ação de determinado Estado, não de determinados indivíduos ou grupos de indivíduos. Os princípios atinentes à teoria da guerra justa fornecem, à ótica de Sehrawat (2016), as bases éticas e legais que governam os conflitos armados.

Neste sentido, a Teoria da Guerra Justa ocupa-se de duas questões elementares, quais sejam: jus ad bellum e jus in bellum (Sehrawat 2016). Em síntese, pode se dizer que "al primero se le denomina ius ad bellum, y consiste en las justificaciones para ir a la guerra, mientras que el segundo, el ius in bell, se centra en los medios que se emplean para hacer la guerra justa” (Frost 2005). Especificamente, a jus ad bellum implica a observância 
de quando é considerado moralmente aceitável para um Estado participar ou iniciar uma guerra; tradicionalmente, para legitimação do ato justo da guerra, dever-se-á atentar a princípios como de justa causa, intenção correta, autoridade apropriada, último recurso, probabilidade de sucesso e proporcionalidade. O jus in bellum, por sua vez, dita as regras de como o combate deve ser travado, atentando a quem está autorizado a empregar a violência e quais são os limites dessa, bem como distinções entre combatentes e não combatentes (Sehrawat 2016).

Ocorre que, antes da elaboração de normas escritas acerca do jus in bellum, ou o direito na guerra, o direito costumeiro internacional já garantia proteção especial a feridos e enfermos, médicos e enfermeiros, hospitais, prisioneiros de guerra e à população civil. Dentre outros textos normativos que surgiram no decurso do tempo, volta-se especial atenção à Convenção de Genebra, de 1864, a qual esculpiu um sistema de normas voltado à proteção dos itens anteriormente elencados, sendo considerado doutrinariamente como o marco inicial do denominado direito humanitário (Rezek 2018, 438-9).

Em 1907, após a segunda conferência internacional da paz, realizada em Haia, surge o chamado "direito de Haia", exprimido em treze convenções que lecionavam acerca do direito de guerra e práticas a serem seguidas num cenário de guerra. Segundo sustenta Rezek (2018, 440-1), sobrevivem algumas normas de limitação dos Estados em guerra, as quais podem ser subdivididas em três princípios limite, quais sejam: (i) "ratione personae", que implica que os não combatentes devem ser poupados; (ii) "ratione loci", que somente são atacáveis localidades que configuram objetivos militares; (iii) "ratione conditionis", que proíbem métodos ou emprego de armas que sejam capazes de provocar sofrimento excessivo ao exército inimigo.

Posteriormente ao Pacto da Sociedade das Nações, de 1919, que não vetou expressivamente a guerra, e ao Pacto Briand-Kellogg, de 1928, que se apresentou como um avanço pela busca de meios pacíficos para a dissolução de conflitos entre Estados, advém a Carta da Organização das Nações Unidas, em 1945, responsável pela reprovação formal da guerra, na forma de seu Art. $2^{\circ}, \$ 4^{\circ}$ (ONU 1945). Sendo a guerra considerada como ato ilícito internacional, atualizou-se o arcabouço legal atinente ao Direito Humanitário, surgindo, para tal propósito, as quatro Convenções de Genebra, pactuadas em 1949, que, à lição de Rezek (2018, 444), ofereciam as seguintes guaridas legais de protegerem: (i) "os soldados postos fora de combate porque feridos, enfermos ou náufragos"; (ii) "os soldados reduzidos ao estatuto de prisioneiros de guerra, em caso de captura ou rendição"; (iii) todos os indivíduos que prestam "serviços de socorro, notadamente médicos e enfermeiros, mas também capelães, administradores 
e transportadores sanitários"; (iv) as pessoas "não combatentes, ou seja, os integrantes da população civil".

Em que pese a distinção protetiva das Convenções supra referidas, estas possuem em comum o seu Art. $3^{\circ}$, o qual pró́be, mesmo em conflitos internos, o emprego de tortura, a tomada de reféns, o tratamento humilhante ou degradante, as condenações e execuções sem julgamento prévio. Neste contexto, surgem dois protocolos adicionais concluídos em Genebra em 1977: O Protocolo I, versando sobre conflitos internacionais; O Protocolo II, tratando de conflitos não internacionais, estendendo a aplicação do Art. $3^{\circ}$ (Rezek 2018, 446).

Os Estados pactuantes de um determinado tratado internacional de Direitos Humanos podem, em situações excepcionais, por força de cláusulas de derrogação, suspender de forma temporária as obrigações contratuais estabelecidas. Um exemplo desta suspensão obrigacional são os tempos de guerra e conflitos armados, sendo o regime regulador jurídico, nestes casos, o denominado Direito Internacional Humanitário, uma vez que, como visto, abrange situações, estabelece regras e limites, bem como garante especial proteção às pessoas e bens afetados pelas hostilidades do conflito armado (Peterke et al. 2009).

Por pertinência ao assunto, interessa apontar que, com a celebração do Estatuto de Roma, em 1998, recepcionado pelo Brasil na forma do Decreto $\mathrm{n}^{\circ} 4.388$, de 25 de setembro de 2002, é criado o Tribunal Penal Internacional, incumbido de julgar crimes de maior gravidade e com alcance internacional - a saber, crimes de guerra, genocídio e crimes contra a humanidade (Peterke et al., 2009). Por sua vez, o Art. $8^{\circ}$, \$2, alínea “a”, do referido Estatuto de Roma, define por crime de guerra "as violações graves às Convenções de Genebra, de 12 de agosto de 1949, a saber, qualquer um dos seguintes atos, dirigidos contra pessoas ou bens protegidos nos termos da Convenção de Genebra” (Brasil 2002).

Ciente do papel do Direito Internacional Humanitário, é de se destacar que, até o momento, não há como transferir a responsabilidade pelo cumprimento das referidas normas a máquinas, eis que as obrigações derivadas de tais diplomas legais são, na realidade, direcionadas às partes componentes do conflito armado, em especial aos combatentes dos Estados envolvidos (ICRC 2016a), não podendo as armas autônomas, na qualidade de objetos inanimados, serem confundidas com partes humanas em um dado conflito bélico. Frise-se: são as pessoas que devem cumprir as obrigações do Direito Internacional Humanitário (Defense Innovation Board 2019). Neste sentido, as LAWS não são diretamente reguladas pelos tratados de Direito Internacional Humanitário, visto que as diretrizes estabelecidas são endereçadas às partes que integram um determinado conflito armado, 
internacional ou não, planejando e executando ataques, bem como defendendo-se desses (Davison 2017, 7).

Sob este aspecto, é relevante destacar que, a priori, o debate acerca do uso das LAWS em consonância com as normas oriundas do Direito Internacional é de notável complexidade, uma vez que, na atualidade, não existe legislação que estabeleça diálogo específico sobre o emprego e desenvolvimento de armas autônomas. O Comitê Internacional da Cruz Vermelha reforça este entendimento, visto que a capacidade de realização de uma revisão legal sobre a matéria depende do entendimento técnico existente acerca da capacidade e efeitos da arma, os quais podem ser apurados, no decurso do tempo, através de análises e testes do sistema autônomo (ICRC 2016b).

Neste contexto, o Art. 36 do Protocolo I da Convenção de Genebra prevê necessidade de revisões legais acerca do uso de novas armas desenvolvidas (Sehrawat 2016). O referido diploma legal indica que, quando um Estado estude, desenvolva, adquira ou adote um novo tipo de arma, meios ou métodos de combate, "terá a obrigação de verificar se seu emprego, em certas condições ou em todas as circunstâncias, estaria proibido pelo presente Protocolo ou por qualquer outra norma de Direito Internacional aplicável” (Brasil 1993).

Com efeito, importa consignar que, conforme preceitua o Art. $1^{\circ}$ (2), do Protocolo I, bem como o preâmbulo do Protocolo II, da Convenção de Genebra, em casos omissos pela lei, devem ser observados como referência os princípios e regras gerais do Direito Internacional Humanitário, provenientes dos costumes, anteriormente destacados, bem como os princípios de humanidade e os ditames de consciência pública (Davison 2017). Por outro lado, Sehrawat (2016) alerta que armas autônomas são notadamente distintas das velhas armas empregadas em conflitos armados, bem como que importa considerar que a velocidade no desenvolvimento das novas tecnologias no campo da informação e da robótica pode fazer com que a legislação aplicada em casos omissos seja insuficiente para balizar totalmente o uso de armas autônomas. Assim, sugere, como solução, a formulação de instrumentos internacionais como: um novo tratado internacional sobre a matéria de armas autônomas; uma convenção das Nações Unidas; ou a elaboração de um novo manual para o desenvolvimento e utilização de armas autônomas (Sehrawat 2016).

Além disso, enquanto não se faz presente legislação específica, que regulamente, de forma direta, o emprego das LAWS, essas, na qualidade de armas e instrumentos de guerra manipulados pelas partes de um conflito armado, devem ser utilizadas em conformidade com os princípios e regras gerais estabelecidos pelo Direito Internacional Humanitário. Neste senti- 
do, as obrigações oriundas do Direito Internacional Humanitário compelem o operador, programador ou o responsável a planejar, realizar e decidir sobre determinada manobra militar, a observância às regras de distinção, proporcionalidade e preocupações atinentes à aplicação de armas autônomas em uma operação militar (Davison 2017) O Conselho de Inovação da Defesa (DIB) dos Estados Unidos da América (2019), neste sentido, aponta que "as regras existentes na Lei da Guerra podem ser aplicadas quando novas tecnologias, como a IA, são utilizadas em conflitos armados” (Defense Innovation Board 2019).

Neste passo, segundo aponta Davison (2017), para que o uso das LAWS ocorra em harmonia com as disposições e cautelas do Direito Internacional Humanitário, deve-se assegurar que o sistema seja capaz de realizar a distinção entre objetivos militares e civis, entre a população civil e os combatentes do conflito, bem como a diferença entre combatentes ativos e aqueles entendidos como fora de combate. Para tanto, importa igualmente determinar se não haverá, por decorrência do ataque, danos à população e bens civis, assim como o exame de atos possíveis de serem considerados excessivos para a vantagem militar da parte, o que equivale a dizer que devem ser observadas as regras atinentes à proporcionalidade. Por fim, caso seja identificada qualquer ação que lesione as regras de distinção e proporcionalidade, numa situação onde se descobre que o alvo na realidade é civil e não militar, impõe-se, por força das normas de precaução no ataque, que este seja passível de suspensão e cancelamento (Davison 2017).

Ademais, Sehrawat (2016) refere que as regras e princípios gerais do Direito Internacional Humanitário demandam a existência de elementos capazes de garantir que o ataque não causará sofrimento desnecessário, com fulcro na disposição do Art. 35, $\$ 2^{\circ}$ do Protocolo I da Convenção de Genebra, que determina que "é proibido o emprego de armas, projéteis, materiais e métodos de combate de tal índole que causem males supérfluos ou sofrimentos desnecessários” (Brasil 1993). As armas autônomas podem causar ferimentos supérfluos e, inclusive, sofrimento a longo prazo para aqueles expostos, fora que podem causar dano severo ao meio ambiente; todavia, a conformidade com tal princípio depende do tipo de arma empregada pela parte do conflito. Para o Direito Internacional Humanitário, importa, ainda, a observância à necessidade militar (baseada em valores e julgamentos de um comandante), a qual, em breve resumo, assegura que combatentes tão somente utilizarão as armas autônomas para ataques contra objetivos militares legítimos (Sehrawat 2016). Assim, a aplicação de IA, direcionada para armamentos, deve ser revisada com o intuito de garantir a consistência com os requisitos legais já existentes, como, por exemplo, o mencionado 
princípio que veda o emprego de armas que causem sofrimento desnecessário (Defense Innovation Board 2019).

Para que o uso das LAWS coexista de forma pacífica com os ditames do Direito Internacional Humanitário, é necessário que se façam presentes certas características técnicas atinentes ao desempenho do sistema, bem como as circunstâncias pretendidas e esperadas do uso das LAWS (ICRC 2016b). Oito são os atributos técnicos elementares listados pelo Comitê Internacional da Cruz Vermelha: (i) a tarefa designada ao sistema; (ii) o tipo de alvo que o sistema atacará; (iii) o ambiente em que o sistema operará; (iv) o movimento do sistema no espaço; (v) o período de tempo (time-frame) de funcionamento do sistema; (vi) a adaptabilidade do sistema (ou seja, a habilidade de adaptar seu comportamento em determinadas mudanças no ambiente, estabelecer suas funções e estipular seus próprios objetivos); (vii) o grau de confiabilidade do sistema, sendo ponderada a sua capacidade de resistência a eventuais falhas ou vulnerabilidade para vulnerabilidade para defeitos ou a ataques de hackers; e (viii) a potencial supervisão humana e sua capacidade para intervenção para desativar o sistema (ICRC 2016a).

A combinação destas oito características culmina em dois elementos indispensáveis para o uso dos sistemas de armas autônomas que respeite o Direito Internacional Humanitário, quais sejam: a previsibilidade (predictability) e, igualmente, confiabilidade (reliability) das LAWS (Davison 2017, 10). Previsibilidade aplicada às LAWS "é o conhecimento de como funcionará em qualquer circunstância de uso, bem como os efeitos que resultarão". Por sua vez, confiabilidade é "a qualidade de ser confiável ou ter um desempenho consistente”. Neste contexto, confiabilidade é o conhecimento de como o sistema funcionará considerando a finalidade para a qual foi criado - por exemplo, sem falhas ou efeitos imprevistos (Davison 2017, 10). Em contrapartida, no que tange à confiabilidade e à segurança do sistema, segundo argumenta Scharre (2017), sistemas de armas autônomos não desviam de seus objetivos, realizando exatamente a tarefa para qual foram programados para desempenhar - o que, de acordo com o autor, faria com que sistemas autônomos fossem mais previsíveis do que humanos em situações de crise (Scharre 2017).

Operações realizadas com sistemas e máquinas podem, assim como com seres humanos, ser falíveis; no entanto, a autonomia em sistemas de armas permite a realização de operações em maior escala, o que poderia agravar consequências indesejadas em casos de acidentes (Scharre 2017). Neste sentido, a criação e o desenvolvimento de sistemas de armas com maior autonomia pode ferir a confiabilidade e previsibilidade do sistema, bem como gerar um significativo risco ao cumprimento das disposições do Direito Internacional Humanitário, na medida em que os sistemas passam 
a ser mais complexos e dotados de elevada autonomia de atuação durante o seu funcionamento. Visto isso, a supervisão humana e, ainda, a existência da possibilidade de intervenção, podem ser consideradas como fatores de diminuição de riscos no uso das LAWS (ICRC 2016a).

Assim sendo, certo nível de controle humano e interferência humana no ciclo de vida da máquina é necessário para o uso das LAWS e para que estas estejam em consonância com as disposições das normas de Direito Internacional Humanitário. O Comitê Internacional da Cruz Vermelha indica que tanto o controle humano com sua interferência devem ser exercidos nos vários estágios da vida do sistema e nas várias formas em que ele se apresenta, com destaque para as seguintes fases: (i) criação, onde ocorre o desenvolvimento e programação do sistema (development stage); (ii) implementação do uso do sistema, situação em que o sistema é ativado pelo operador (activation stage); (iii) supervisão - e possibilidade de intervenção humana - durante a operação do sistema de armas durante um ataque, identificando e, por conseguinte, neutralizando o alvo selecionado (operation stage) (ICRC 2016a).

Pertinente dispor que é no terceiro estágio, quando a arma está em funcionamento e, portanto, tem autonomia para selecionar e atacar alvos, que se verifica se o controle humano nos dois estágios anteriores é considerado suficiente para superar a necessidade de intervenção humana, ainda que mínima, sob uma perspectiva legal e ética (ICRC 2016a). No que tange a sistemas de IA, Zanzotto (2019) entende que uma forma de manter os humanos no "loop" é por meio da programação do sistema e da explicação de decisões resultantes de "machine learning", dando a palavra final a humanos (especialistas em determinada área, que alimentam o sistema) e explicando quais as fontes de dados foram responsáveis pela conclusão do sistema (Zanzotto 2019, 243-52).

Ademais, o Conselho de Inovação da Defesa (DIB) dos Estados Unidos da América (2019) propôs uma série de princípios para o uso ético e responsável de IA, voltados tanto para sistemas de combate quanto aos não desenvolvidos para este fim, que receberam aprovação unânime do Conselho (Vergun 2019). Os referidos princípios demandam certo nível de responsabilidade pelo desenvolvimento, implantação e uso de um sistema de IA, voltado ou não para o combate bélico, estabelecendo um nível adequado de conhecimento técnico sobre a matéria, medidas para adotar vieses não intencionais em sua aplicação e, dentre outros, a aplicação de metodologias transparentes e auditáveis, resumindo-se em cinco princípios de uso e desenvolvimento, quais sejam: (i) responsável (responsible); (ii) equitativo (equitable); (iii) rastreável (traceable); (iv) confiável (reliable); e (v) governável (governable) (Defense Innovation Board 2019). 
Por fim, no que tange à responsabilidade por desrespeito e infrações às normas de Direito Internacional Humanitário, cabe destacar que, caso ocorra evento danoso decorrente do uso das LAWS, será o Estado responsabilizado por atos errôneos e violações a direitos humanos, bem como será igualmente responsabilizado caso faça uso de um sistema de armas não testado ou sem a devida revisão técnica, anterior a sua implantação (ICRC 2016b).

\section{PERSPECTIVAS ÉTICAS ACERCA DO USO DAS LETHAL AUTONOMOUS WEAPON SYSTEM}

O fascínio e as expectativas que acompanham as LAWS também provocam posições bem menos receptivas, que vão desde um razoável apelo à precaução diante da incerteza científica dos riscos e potenciais danos, à alegação de uma imediata moratória para as armas autônomas diante de prognósticos pessimistas. Scherer (2016, 362), ao falar de riscos, faz o alerta de que o mau prognóstico geralmente está relacionado a "sistemas que buscam maximizar a utilidade de sua função, mesmo quando essa maximização possa representar uma ameaça existencial à humanidade".

Veja-se, por exemplo, que historicamente a aplicação de princípios de humanidade e ditames de consciência, tais como os mencionados no Art. $1^{\circ}, \S 2^{\circ}$, do Protocolo I e no preâmbulo do Protocolo II das Convenções de Genebra, anteriormente expostos, em objetivos militares tem se mostrado dificultosa e, por outro lado, a capacidade de sistemas de armas autônomas em aderir a padrões de condutas éticas mostra-se ainda menos garantida. Isso ocorre em razão da preferência da indústria bélica em desenvolver sistemas de armas autônomas com superioridade - e inclinação — tática, não havendo motivo prático para que os designers das LAWS restrinjam seu potencial letal. Sob a perspectiva de Zawieska $(2017,52)$, “o uso de armas autônomas pode, em outras palavras, conduzir a guerras desumanamente eficientes”.

É por esse motivo que, para Sullins (2011), deveria ter sido ampliada a discussão ética sobre todos os problemas de programação de algoritmos antes de possibilitar que as LAWS tomem decisões de vida e morte. Frente ao exposto, o autor levanta os seguintes questionamentos: armas de guerra podem ser usadas eticamente, programando regras de guerra, normas de guerra e teorias de guerra na própria máquina? Como os algoritmos devem ser programados para ajudar os combatentes de guerra a tomar decisões sólidas e éticas? O que acontece quando esses sistemas se tornam mais autônomos? É possível afirmar que os humanos sempre estarão no comando para indicar como um robô deve usar força letal? Como uma máquina determina se está em uma situação eticamente carregada? E, assu- 
mindo que pode lidar com esse problema, qual sistema ético deve usar para ajudar a tomar sua decisão? Para Sullins (2011), não está fora de questão que uma ética da IA seja possível; entretanto, o autor alerta para o fato de que a humanidade ainda está muito carente de detalhes para responder às questões levantadas com dados confiáveis e precisos.

A estes questionamentos podem ser somados os levantados por Martin (2018, 87): os robôs podem ser agentes morais? Existe um dever de "cuidado" entre eles? Em que situações seria possível justificar que um robô respeita a vontade humana? São lacunas que passam a exigir que o olhar se volte para as contribuições de grandes pensadores que deixaram um legado filosófico para que o ser humano do século XXI possa refletir diante de um cenário que se descortina com o avanço da tecnociênica. Assim, para os objetivos do presente estudo, buscar-se-á um fio comum e um diálogo com a tradição e em especial com filósofos que se dedicaram a mostrar a importância de trilhar um caminho alicerçado na ética do cuidado e da prudência como Aristóteles, Kant, Heidegger e Jonas — sem a intenção de desconsiderar a relevância de outros pensadores que se dedicam a estudar esta área do conhecimento.

A ética aristotélica, embora cronologicamente distante dos avanços das novas tecnologias, tem sua atualidade por possibilitar respostas possíveis e coerentes aos grandes problemas éticos do uso de LAWS. Por ser uma ética das virtudes morais e da prudência na busca da perfeição do agente moral, a ética aristotélica suscita interesse por permitir sempre novas interpretações. O que interessa particularmente é a virtude da prudência (phroronesis), como a virtude intelectual da boa liberação, entendida como racionalidade prática ou sabedoria prática. Em Aristóteles (2001, Livro VI), não há autêntica virtude ética sem a prudência e, ao mesmo tempo, não há prudência sem virtude ética. A prudência aristotélica é a boa deliberação, a sabedoria prática para determinar o que deve ou não ser feito. Além de ser universal, a prudência em Aristóteles também "deve conhecer as circunstâncias particulares, porque ordena a ação, e a ação se refere às coisas particulares" (Aristóteles, 2001, 1.140a). Para o filósofo, a ação prudente não é um ato cognoscitivo puro, ou seja, ser prudente não é apenas conhecer o que se deve fazer, mas também ser capaz de praticá-la, por isso a prudência é ao mesmo tempo um ato virtuoso no sentido intelectual (um acerto) e moral (uma bela ação) (Aristóteles, 2001, 1.140b). Prudência ou sabedoria prática, como Reale (1994, 417-8) prefere usar, é a virtude responsável por "dirigir corretamente a vida do Homem, isto é, em saber deliberar sobre o que é bom ou mau para o Homem”.

É significativo observar que Kant (1964), ao construir uma nova teoria ética fundamentada na moral e no Direito, instigou o ser humano a se 
conscientizar de sua posição no mundo na ideia do indivíduo responsável pela humanidade. Ao fundamentar uma moral autônoma, Kant parte de imperativos categóricos assentados em princípios a priori motivados por um profundo sentido de dever, e essa construção o apresenta como precursor da moral moderna. Com Kant (1964), o "outro" passa a ter um valor moral pelo "princípio da humanidade em si”. Essa visão vai marcar profundamente a filosofia. A autonomia fundamenta a dignidade da natureza humana e vincula-se à liberdade e ao princípio universal da moralidade.

Um dos pilares do edifício ético construído por Kant (1964, 129), na obra Fundamentação da Metafísica dos Costumes, é o imperativo ético "age apenas segundo uma máxima tal que possas ao mesmo tempo querer que ela se torne lei universal”. Este imperativo reflete que o essencial para cada ser humano, antes de pensar em fazer ou não fazer algo, é inicialmente refletir se deseja que essa ação se torne uma regra universal. A resposta não pode estar pautada pelos padrões sociais ou pela necessidade local mas, sim, na natureza humana universal. Outro pilar de sua ética está no imperativo categórico "age de tal modo que uses a humanidade, ao mesmo tempo na tua pessoa e na pessoa de todos os outros, sempre e ao mesmo tempo como um fim, e nunca apenas como um meio". Neste sentido, o filósofo vai dizer que o "violador dos direitos dos homens tenciona servir-se das pessoas dos outros simplesmente como meios, sem considerar que eles, como seres racionais, devem ser sempre tratados ao mesmo tempo como fins, isto é, unicamente como seres que devem poder conter em si o fim desta mesma ação" (Kant 1964, 230).

De Heidegger, o que interessa ao presente estudo é o tema do cuidado e do seu questionamento sobre a técnica. Ele desenvolve uma crítica filosófica para mostrar que a técnica está vinculada com o destino do ser que se dá na temporalidade. Questionar a técnica é, para o filósofo alemão, preparar uma livre relação com ela, e isso se dá ao explorar as hipóteses mais extremas dos perigos que uma técnica pode representar ao destino planetário da humanidade. Daí seu dizer "Quanto mais nos aproximarmos do perigo, de modo mais claro começarão a brilhar os caminhos para o que salva, mais questionadores seremos. Pois o questionar é a devoção do pensamento" (Heidegger 2007, 396). É com o cuidado do ser como um modo fundamental do existir que Heidegger (1983) alicerça toda sua fenomenologia, e é pelo cuidado que o homem tem novamente a possibilidade de reconduzir seu pensar para sua essência enquanto ser-no-mundo e ser-com-mundo.

Jonas, discípulo de Heidegger, levou a sério a convocação de seu mestre para estruturar sua "ética do cuidado" ao desenvolver o "princípio responsabilidade". O filósofo parte do imperativo ético kantiano do ser humano como seu próprio legislador para dizer que o princípio já não é suficiente diante do 
poder tecnológico que está à sua disposição. Para o autor, a ética tradicional não instruiu o homem sobre “as normas do 'bem' e do 'mal' às quais se devem submeter as modalidades inteiramente novas do poder e de suas criações possíveis" (Jonas 2006, 21). Ao reconhecer que é necessário avançar, Jonas (2006, 21) propõe o "princípio responsabilidade" dirigido à dimensão pública e aos domínios da ação política pública como princípio orientador para as decisões dos governantes e dos desenvolvedores de novas tecnologias, pois a aventura tecnológica se tornou "uma terra de ninguém".

Em Jonas (2006, 123), responsabilidade é "uma função do poder e do conhecimento". A sofisticação e a complexidade das novas tecnologias geram um aumento inigualável de poder, perigos e riscos transtemporais, transterritoriais e transgeracionais. Com promessas muitas vezes utópicas e ameaças apocalípticas, a técnica em Jonas se torna uma questão ética, pois carrega um poder em si mesma que passa a exigir um "poder sobre o poder" (Jonas 2013, 75). Avaliar o poder da técnica antes que ela seja empregada e vigiar o poder de si mesmo é proposto por Jonas $(2013,75)$ como prudência e obrigação ética, abrindo assim o caminho para um avanço com precaução enquanto não existirem projeções seguras sobre a irreversibilidade de muitos processos tecnológicos em curso. Dito de outro modo, é preciso ficar atento para seu lado ameaçador "que a longo prazo poderia ter a última palavra”. Com esse dizer, Jonas $(2013,52)$ denuncia que "à técnica está negado o livre espaço da neutralidade ética”. Ter responsabilidade com a autonomia concedida para as LAWS é certamente uma responsabilidade ética que a técnica confiou ao ser humano em nome de dimensões remotas, futuras e globais (Jonas 2013, p. 53).

De fato, a implementação, utilização e desenvolvimento de sistemas de inteligência artificial, tal como as LAWS, está em que a IA não somente deve passar pelo crivo das normas e regimentos legais, mas, igualmente, dever-se-á observá-las sob a perspectiva de uma nova ética, baseada na prudência, no cuidado, na precaução e na responsabilidade das presentes gerações para com as gerações vindouras, como preceitua Jonas.

Importa dizer que a reflexão ética sobre o uso e os propósitos das LAWS encontra-se desafiada por uma curta trajetória científica. Zawieska (2017) é um dos autores que vem estudando o tema. Em sua análise de uma ética das LAWS, Zawieska (2017,52-4) elenca dois tópicos, quais sejam: (i) a analogia entre o homem e a máquina; e (ii) a constante demanda por melhoria. A primeira concerne à semelhança presente nos sistemas de armas autônomas existentes, ou seja, a autonomia. A segunda, por sua vez, atine a crença de que sistemas de IA poderão superar seres humanos inclusive na aplicação da ética, que para muitos tecnocientistas é entendida como um mero "protocolo ético" ou um "processo ético". Esta percepção leva à cren- 
ça paliativa de que, inclusive no que tange à ética, a melhoria somente será alcançada através da implantação de sistemas autônomos, uma vez que humanos não são capazes de agir sempre de forma ética. Entretanto, como afirma Zawieska $(2017,55)$, "essa postura não reflete a experiência moral ou ética humana real, e seria um erro esperar que máquinas sejam uma versão melhor dos seres humanos”. Na mesma linha Zawieska adverte que:

O poder que esta analogia já exerce sobre nosso mundo dispõe um claro aviso: permitir ou não que sistemas autônomos tomem decisões de vida ou morte em nosso nome modelará não apenas os resultados políticos e militares, mas, também, a nossa autoconcepção como seres humanos. Tirando humanos do ciclo de batalha, corre o risco de "perder a humanidade" em um sentido amplo; nas palavras de uma declaração para o Conselho de Direitos Humanos das Nações Unidas: “tirando os humanos do 'loop', também se corre o risco de tirar a humanidade do "loop”. (Zawieska 2017, 54, tradução nossa).

Jonas (2006), neste sentido, também aconselha a observância da primazia do mau prognóstico sobre o bom, uma vez que o sucesso no desenvolvimento tecnológico pode tratar-se de uma aposta jogada às incertezas do futuro e em grandes causas, as quais têm a capacidade de atingirem os fundamentos do empreendimento humano, bem como são irreversíveis, trazem incertezas e perigos totalmente novos. A própria dinâmica compulsiva do desenvolvimento tecnológico rouba das mãos do ser humano as rédeas da ação. Tem-se a liberdade para dar o primeiro passo, mas a humanidade torna-se escrava do "segundo e de todos os passos subsequentes”. Somados os velozes efeitos da ação humana e a sua incapacidade do saber para prognósticos de longo prazo, dever-se-á dar mais peso à ameaça (profecia da desgraça) do que à promessa utópica do sucesso (profecia da salvação) (Jonas 2006, 77-8).

No campo militar e de seguridade, Rodriguez $(2018,166)$ indica que as reflexões devem estar pautadas no "princípio da responsabilidade para com a humanidade e para com o futuro". Seguir os ensinamentos de Jonas para garantir "os direitos e a dignidade dos seres humanos, como dita o Direito Internacional Humanitário (DIH)” é outra aposta de Rodriguez (2018, 166), pois instigam a pensar em alternativas éticas, políticas e jurídicas. As LAWS tendem a se autonomizar, podendo os efeitos de sua aplicação adquirir uma dinâmica compulsiva, tornando-se "não só irreversíveis como também autopropulsionados, ultrapassando em muito aquilo que os autores quiseram e planejaram" (Jonas 2006, 78-9).

A preocupação ética com os avanços da IA foi o propósito para a criação no ano de 2018 de um grupo independente de peritos de alto nível no âmbito da Comissão Europeia resultando na publicação do guia de "Orientações 
éticas para uma IA de confiança”. São três os componentes que devem ser observados ao longo do ciclo de vida do sistema para uma IAM de confiança: (i) deve ser legal, ou seja, deve cumprir "toda a legislação e regulamentação aplicáveis; (ii) deve ser ética, garantindo a observância de princípios e valores éticos; e (iii) deve ser sólida, tanto do ponto de vista técnico como do ponto de vista social, uma vez que, mesmo com boas intenções, os sistemas de IA podem causar danos não intencionais". Logo, os sistemas de IA devem estar "centrados no ser humano e assentados no compromisso de serem utilizados a serviço da humanidade e do bem comum”. A partir destes pressupostos, o Grupo propôs nove princípios éticos: respeito da dignidade humana; liberdade do indivíduo; respeito da democracia, da justiça e do Estado de Direito; igualdade, não discriminação e solidariedade; direitos dos cidadãos; respeito da autonomia humana; prevenção de danos; equidade (EU 2018, 2-14).

Ainda que assumam a forma de acordos entre os países que integram a União Europeia, proposto e aceito por um grupo independente de peritos, o Guia e outros acordos internacionais refletem, como bem explica Ferrari (2010), uma frouxidão legal esperada quando se busca a regulação de novas tecnologias. A grande contribuição do debate ético é o avanço em temas como limites da tecnociência, o engajamento público de todos os atores, a necessária precaução, a análise de risco e a necessidade de regulação e governança global. No entanto, em relação às LAWS observa-se que o debate é incipiente e não alcança a complexidade dos riscos e da dinâmica dos interesses envolvidos.

Frente ao exposto, é imprescindível que a "prudência” professada por Aristóteles, o "princípio da humanidade em si" de Kant, o "cuidado" em Heidegger e o princípio responsabilidade de Jonas, balizem o uso e desenvolvimento das LAWS, a fim de assegurar o seu uso de forma legal e ética, bem como para que não se sucedam apostas totais capazes de colocar em xeque a condição humana ou mesmo capazes de, em momento oportuno, desrespeitá-la. O mau uso das LAWS pode ser dramático para a humanidade e não possibilitar tempo para autocorreções. Como se trata do destino da humanidade, o retorno à tradição e aos preceitos éticos aqui discutidos pode ser um caminho contra os abusos do poder humano.

\section{CONSIDERAÇÕES FINAIS}

As oportunidades apresentadas pelas LAWS são de grande alcance e sem precedentes na história da humanidade. Com movimentos tímidos, o entusiasmo por esta revolução e seus riscos têm resultado em preocupações no campo ético, político e militar. Entretanto, a maioria das discussões 
frente às novas tecnologias ainda é "post rem, ou seja, uma reação posterior ao dano já causado, ou no mínimo posterior à invenção ou inovação já realizada” (Brüseke 2005, 7). Heidegger (1991, 35) já argumentava pela premência de uma aspiração por uma ética ao posicionar que, quanto mais a perplexidade do alcance da técnica se manifesta, mais o ser humano deveria dedicar "todo o cuidado à possibilidade de criar uma Ética de caráter obrigatório”. Na elaboração do princípio responsabilidade, Jonas (2013, p. 171) indica que deve-se "ir fundo e examinar o uso eventual dos poderes antes mesmo de eles estarem completamente prontos para o uso".

As Lethal Autonomous Weapon Systems são armas autônomas, capazes de identificar determinados tipos de alvos e atacá-los sem qualquer tipo de intervenção humana, isto por força de sua autonomia derivada, em suma, de três características: self-governance, machine learning e decision-making. $\mathrm{O}$ desenvolvimento, pesquisa e uso das LAWS descambam em pertinentes e atuais questões acerca do uso deste tipo de armamento em consonância com o Direito Internacional Humanitário e a Ética, tais como a capacidade ética da máquina para tomar decisões de vida ou morte. O mau uso pode gerar uma condição de irreversibilidade, o que, conjugada com a agregação de sua magnitude, acabam gerando novos desafios para a ética da responsabilidade.

Neste sentido, conclui-se que, para que o uso das LAWS esteja em harmonia com os ditames do Direito Internacional Humanitário e os preceitos éticos do cuidado e da prudência aqui expostos, faz-se necessária a observância de dois elementos indispensáveis, quais sejam: (i) a previsibilidade do sistema (predictability); e (ii) a confiabilidade do sistema (reliability). Tais requisitos são satisfeitos à medida que se verifica a existência dos oito atributos técnicos elencados pelo Comitê Internacional da Cruz Vermelha. Certo nível de controle humano (para intervir e supervisionar) igualmente é recomendado para assegurar os referidos requisitos, sendo considerado um fator de diminuição de riscos. A ética tem algo a dizer sobre a técnica, principalmente, quando se trata das LAWS, que colocam a natureza humana numa situação de vulnerabilidade inédita.

Por outro lado, é evidente que não se pode aguardar a ocorrência de um desastre, um genocídio ou algo similar para que o Direito Internacional Humanitário e a ética passem a se interessar pelas LAWS, que se encontram em franca expansão global. Para fazer frente ao pior cenário, Hans Jonas sugere uma nova perspectiva ética baseada na análise política e jurídica das futuras gerações, fundada, pois, na responsabilidade decorrente do avanço desenfreado do desenvolvimento tecnológico - observando, para tanto, os efeitos e consequências maléficos da ação humana no amanhã. 
Desta forma, impõe-se uma atitude de cuidado, prudência e respeito à ética da responsabilidade, conforme preceituado por Aristóteles, Kant, Heidegger e Jonas. Acatando os requisitos técnicos capazes de dar confiabilidade e previsibilidade aos sistemas de armas autônomos, é, a priori, possível o uso das LAWS em consonância com os ditames do Direito Internacional Humanitário e, por decorrência, da ética.

\section{REFERÊNCIAS}

Altenburg;Mesquita,Evandro Tinoco,eClaudio Tinoco Mesquita.2019. Inteligência Artificial em Cardiologia: Conceitos, Ferramentas e Desafios - "Quem Corre é o Cavalo, Você Precisa ser o Jóquei”. Arq. Bras. Cardiol. 14. Ahead of print. Epub. http://www.scielo.br/scielo.php?pid=So066-782X2019005022 109\&script=sci_

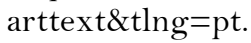

Aristóteles. 2001. Ética a Nicômacos. Tradução de Mário da Gama Kury. 4. ed. Brasília: Editora Universidade de Brasília.

Arkin, Ronald C. 2017. "A robotocist's perspective on lethal autonomous weapon systems". Perspectives on Lethal Autonomous Weapon Systems 30 (November): 35-47. https://www.unog.ch/80256EDD006B8954/(httpAssets)/6866E44ADB996042C12581D400630B9A/\$file/op30.pdf

Asaro, Peter. 2012. "On banning autonomous weapon systems: human rights, automation, and the dehumanization of lethal decision-making". International Review of the Red Cross 94, no. 886 (Summer): 687-709. doi:10.1017/S1816383112000768

Boulanin, Vincent. 2016. Mapping the development of autonomy in weapon systems: A primer on autonomy (December). Solna, Sweden: SIPRI.

https://www.sipri.org/sites/default/files/Mapping-development-autonomy-inweapon-systems.pdf

Brasil. 1993. Decreto $n^{\circ} .849$, de 25 de junho de 1993. http://www.planalto.gov.br/ ccivil_03/decreto/1990-1994/Do849.htm.

2002. Decreto $n^{\circ} .4388$, de 25 de setembro de 2002. http://www.planalto.gov. br/ccivil_03/decreto/2002/D4388.htm

Davison, Neil. 2017. "A Legal Perspective: Autonomous weapon systems under international humanitarian law". Perspectives on Lethal Autonomous Weapon Systems, no. 30 (November): 5-18. https://www.unog.ch/80256EDDo06B8954/(httpAssets)/6866E44ADB996042C12581D400630B9A/\$file/op30.pdf 
Defense Innovation Board. 2019. AI Principles: Recommendations on Ethical Use of Artificial Intelligence by the Department of Defense. https://admin.govexec. com/media/dib_ai_principles_-_supporting_document_-_embargoed_copy_ (oct_2019).pdf.

Faggella, Daniel. 2018. "What is Artificial Intelligence? An Informed Definition, Emerj Artificial Intelligence Research. TechEmergence (December). https://emerj. com/ai-glossary-terms/what-is-artificial-intelligence-an-informed-definition/

Ferrari, Arianna. 2010. "Developments in the Debate on Nanoethics: Traditional Approaches and the Need for New Kinds of Analysis". NanoEthics 4, no. 1: 27-52. https://link.springer.com/article/10.1007/s1 1569-009-0081-z

Frost, Mervyn. 2005. Ética y guerra: más alla de la teoria de la guerra justa. Revista Académica de Relaciones Internacionales, no. 3, (Octubre): 1-27. https://revistas.uam.es/index.php/relacionesinternacionales/article/view/4840/5309.

Hagstörm, Martin. 2016. "Characteristics of autonomous weapon systems". Autonomous Weapon Systems: Implications of Increasing Autonomy in the Critical Functions of Weapons. Expert meeting, Geneva, Switzerland: ICRC (15-16 March): 23-25. https://shop.icrc.org/autonomous-weapon-systems.html? store $=$ fr\& $\mathrm{ga}=2.36932896 .1627033310 .1572366031-1120845335.1572366031$

Heidegger, Martin. 1983. "O fim da filosofia e a tarefa do pensamento". Conferências e escritos filosóficos (Os Pensadores). Traduzido por Ernildo Stein. 2. ed. São Paulo: Abril Cultural.

. 1991. Carta Sobre o Humanismo. Tradução de Rubens Eduardo Frias. São Paulo: Moraes.

2007. "A questão da técnica". Scientice Zudia 5, no. 3, 375-98. São Paulo.

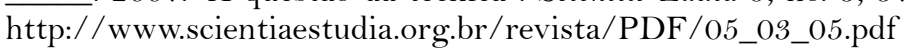

ICRC. 2016a. Views of the ICRC on autonomous weapon systems. Convention on Certain Conventional Weapons Meeting of Experts on Lethal Autonomous Weapons Systems (LAWS), Geneva, 11-16 April 2016. https://www.icrc.org/en/ document/views-icrc-autonomous-weapon-system

ICRC. 2016b. Autonomous weapon systems implications of increasing autonomy in the criticalfunctions of weapons. Versoix, Switzerland. https://shop.icrc.org/autonomous-weapon-systems.html? store=fr\&_ga $=2.36932896 .1627033310 .1572366031$ 1120845335.1572366031 .

Inovação Tecnológica. 2019. "Robótica”. Informática. https://www.inovacaotecnologica.com.br/index.php. 
Jonas, Hans. 2006. O princípio responsabilidade: Ensaio de uma nova ética para civilização tecnológica. Rio de Janeiro: Contraponto; Ed. PUC-Rio.

Jonas, Hans. 2013. Técnica, medicina e ética. Sobre a prática do princípio responsabilidade. Tradução de Grupo de Trabalho Hans Jonas da ANPOF. São Paulo: Paulus.

Kant, Immanuel. 1964. Fundamentação da Metafísica dos Costumes. Tradução e notas de Antônio Pinto de Carvalho. São Paulo: Companhia Editorial Nacional.

Legg, Shane, and Marcus Hutter. 2006. "A formal measure of machine intelligen$c e$, In Proc. 15th Annual Machine Learning Conference of Belgium and The Netherlands (May): 73-80. https://arxiv.org/abs/cs/0605024v 1

Lele, Ajey. 2016. Missile-androcket-defenceweaponsystems. AutonomousWeapon Systems: Implications of Increasing Autonomy in the Critical Functions of Weapons. Geneva, Switzerland: ICRC (15-16 March): 31-32. https://shop.icrc.org/autonomous-weapon-systems.html?__store $=$ fr\&_ga $=2.36932896 .1627033310 .1572366031$ 1120845335.1572366031

2017. "A military perspective on lethal autonomous weapon systems". Perspectives on Lethal Autonomous Weapon Systems, no. 30 (November): 57-61. https://www.unog.ch/80256EDDo06B8954/(httpAssets)/6866E44ADB996042C12581D400630B9A/\$file/op30.pdf

Martin, Nuria Belloso. 2018 . "La Necesaria Presencia de la Ética en la Robótica: La Roboética y su Incidencia en los Derechos Humanos". Cadernos do Programa de Pós-Graduação Direito/UFRGS 13, no. 2, p. 81-121. https://seer.ufrgs.br/ppgdir/ article/view/90165.

ONU. 1994. Carta das Nações Unidas. Assinada em 26 de junho de 1945. https:// nacoesunidas.org/carta/cap1/

Peterke, Sven. 2009. "Parte 1: Doutrinas Gerais”. Manual Prático de Direitos Humanos Internacionais. Brasília: Escola Superior do Ministério Público da União. 96-181. https://www.ufrgs.br/cedop/wp-content/uploads/2014/04/Manual_ Pratico_Direitos_Humanos_Internacioais-1.pdf

Reale, Giovanni. 1994. História da Filosofia Antiga. v. 2. Tradução de Marcelo Perine e Henrique C. Lima Vaz. São Paulo: Loyola.

Rezek, Francisco. 2018. Direito internacional público: curso elementar. 17. ed. São Paulo: Saraiva. 
Righetti, Ludovic. 2016. "Emerging technology and the future autonomous weapons". Autonomous Weapon System: Implications of Increasing Autonomy in the Critical Functions of Weapons. Expert meeting, Geneva, Switzerland: ICRC (15-16 March): 36-39. https://shop.icrc.org/autonomous-weapon-systems.html? store $=$ fr\& $\mathrm{ga}=2.36932896 .1627033310 .1572366031-1120845335.1572366031$

Rodriguez, Antonio Luis Terrones. 2018. "Inteligencia Artificial y ética de la Responsabilidad. Cuestiones de Filosofía 4, no. 22: 141-70. https://doi. org/10.19053/01235095.v4.n22.2018.8311

Roff, Heather. 2016. "Sensor-fused munitions, missiles and loitering munitions". Autonomous Weapon Systems: Implications of Increasing Autonomy in the Critical Functions of Weapons. Expert meeting, Geneva, Switzerland: ICRC (15-16 March): 33-35. https://shop.icrc.org/autonomous-weapon-systems.html? store $=$ fr $\&$ $\mathrm{ga}=2.36932896 .1627033310 .1572366031-1120845335.1572366031$

Russel, Stuart J., and Peter Norvig. 2009. Artificial Intelligence: A Modern Approach. New Jersey: Prentice Hall; Englewood Cliffs. E-book.

Scharre, Paul. 2017. "A security perspective: Security concerns and possible arms control approaches". Perspectives on Lethal Autonomous Weapon Systems, n. 30: 19-33. https://www.unog.ch/80256EDDo06B8954/(httpAssets)/6866E44ADB996042C12581D400630B9A/\$file/op30.pdf

Scherer, Matthew U. 2016. "Regulating Artificial Intelligence Systems: Risks, Challenges, Competencies, and Strategies". Harvard Journal of Law \& Technology 29, no. 2 (Spring): 353-400. http://jolt.law.harvard.edu/articles/pdf/v29/29HarvJLTech353.pdf

Schwab, Klaus. 2018. Aplicando a Quarta Revolução Industrial. Traduzido por Daniel Moreira Miranda. São Paulo: Edipro.

Sehrawat, Vivek. 2016. "Autonomous weapon system: Law of armed conflict (LOAC) and other legal challenges". Computer Law \& Security Review: The International Journal of Technology Law and Practice, (Elsevier). DOI: 10.1016/j. clsr.2016.11.001

Souza Filho, Erito Marques de, Fernando de Amorim Fernandes, Soares, Celine Lacerda de Abreu, Flavio Luiz Seixas, Alair Augusto Sarmet M.D. dos Santos, Ronaldo Gismondi, and John P. Sullins. 2011. "Introduction: Open Questions in Roboethics". Philosofy \& Technology 24, no. 233. https://link.springer.com/article/10.1007/s13347-011-0043-6.

Sullins, John P. 2011 . "Introduction: Open Questions in Roboethics", Philosofy \&ా Technology 24: 233-238. https://link.springer.com/article/10.1007/s13347-011- 
0043-6. União Europeia (EU). 2018. Comissão Europeia. Grupo de peritos de alto nível sobre a inteligência artificial. Orientações Éticas para uma IA de Confiança. Bruxelas.

United Nations. 2015. Study on Armed Unmanned Aerial Vehicles - Prepared on the Recommendation of the Advisory Board on Disarmament Matters. New York: United Nations.

Vergun, David. 2019. Defense Innovation Board Recommends AI Ethical Guidelines. U.S. Dept. of Defense. https://www.defense.gov/Explore/News/Article/ Article/2006646/defense-innovation-board-recommends-ai-ethical-guidelines/

Veruggio, Gianmarco, and Fiorella Operto. 2016. "Roboethics: a bottom-up interdisciplinary discourse in the field of applied ethicis in robotics". International Review of Information Ethics, v. 6. https://www.infodata-edepot.de/volltext/ ijie/07241.pdf.

Vignard, Kerstin. 2016. "Addressing the challenges raised by increased autonomy". Autonomous Weapon Systems: Implications of Increasing Autonomy in the Critical Functions of Weapons. Expert meeting, Geneva, Switzerland: ICRC (15-16 March): 65-68. https://shop.icrc.org/autonomous-weapon-systems.html? store $=$ fr\&_ $\mathrm{ga}=2.36932896 .1627033310 .1572366031-1120845335.1572366031016$

Zanzotto, Fabio Massimo. 2019. "Human-in-the-loop Artificial Intelligence". Journal of Artificial Intelligence Research v. 64: 243-252.https://arxiv.org/ abs/1710.08191

Zawieska, Karolina. 2017. "An ethical perspective on autonomous weapon system”. Perspectives on Lethal Autonomous Weapon Systems, no. 30 (November): 35-47. https://www.unog.ch/80256EDDo06B8954/(httpAssets)/6866E44ADB996042C12581D400630B9A/\$file/op30.pdf 


\section{RESUMO}

Este artigo discute o uso de Lethal Autonomous Weapon System (armas autônomas capazes de detectar e atacar alvos sem intervenção humana, detendo capacidade de autogoverno) que põe em xeque conceitos éticos e do Direito Internacional Humanitário, pela sua autonomia para realizar a tomada de decisões, como de vida ou morte.

Palavras-chave: Inteligência Artificial; Direito Internacional Humanitário; Lethal Autonomous Weapon System; Ética.

\section{ABSTRACT}

This article aimed to discuss the use of the Lethal Autonomous Weapon System (autonomous weapons capable of detecting and attacking targets without human intervention, having capability of self-governance) that undermine ethic concepts and International Humanitarian Law, for their autonomy to make decisions, such as matters of life or death ones.

Keywords: Artificial Intelligence; International Humanitarian Law; Lethal Autonomous Weapon System; Ethic. 